Curr Opin Behav Sci. 2016 August ; 10: 102-107. doi:10.1016/j.cobeha.2016.05.009.

\title{
Executive function and early childhood education
}

\author{
Clancy Blair \\ Department of Applied Psychology, Steinhardt School of Culture, Education, and Human \\ Development, New York University, United States
}

\begin{abstract}
Executive function, a term encompassing domain general cognitive processes associated with working memory, inhibitory control, and the flexible shifting of attention is widely studied in research in neuropsychology and cognitive neuroscience. Only within the last two decades have researchers examined the development of these cognitive abilities in typical child populations. A growing body of research indicates that executive function abilities develop rapidly in early childhood, are important contributors to school readiness and early school success, and are highly relevant to early educational programs for children in poverty.
\end{abstract}

\section{Background and neural basis}

Executive function (EF) refers to domain general psychological processes associated with working memory, inhibitory control, and the flexible shifting of attention. These cognitive abilities are important for coordinating multiple sources of information in the service of purposeful, goal direct behavior [1]. This coordinating function is consistent with the neurobiology of $\mathrm{EF}$ and is reflected in the origin of the $\mathrm{EF}$ construct in neuropsychological research. EF is associated with specific areas of the brain's prefrontal cortex, or PFC, and connectivity of PFC with multiple regions throughout the brain [2]. As such, a substantial literature going back several decades indicates that individuals with damage to specific areas of PFC experience profound difficulty with even very simple tasks requiring the identification of relations among problem elements or the inhibition of highly learned, automatic responses to stimulation [3,4]. Somewhat more recently, within the past 10-20 years, research on the development of EF in typical child populations and on relations between individual differences in EF and primary developmental outcomes of childhood, including cognitive, social-emotional, and academic, has increased exponentially.

\section{EF and child development}

One substantial area of interest has been the relation of EF to school readiness and early adjustment to school. An early paper [5] noted the manifest overlap between the requirements of early elementary schooling and the abilities that characterize EF; namely, holding information in mind and working with it repeatedly over short periods of time;

\footnotetext{
The author has no conflicts of interest and is not aware of any affiliations, memberships, funding, or financial holdings that might be perceived as affecting the objectivity of the research reported here.

Edited by Dénes Szúcs, Fumiko Hoeft and John DE Gabrieli
} 
inhibiting impulsive or highly learned incorrect responses in favor of less dominant, correct responses; being able to see things from multiple perspectives and to shift flexibly among these; and to manage emotion and attention in order to maintain an appropriate level of arousal and interest. The potential importance of this overlap was bolstered by the observation in neuropsychological research that individuals with damage to PFC exhibit profound deficits in EF, including problems with the regulation of emotion and attention, even in the presence of normal or typical IQ [6]. Within this empirical framework, EF has been shown in numerous studies to predict educational outcomes over and above measures of intelligence and/or prior ability [7-11].

\section{Measurement of EF in childhood}

The application of EF to research in education built upon pioneering work in the measurement of EF in young children. The development and validation of a relational setshifting task appropriate for preschoolers clearly demonstrated a developmental progression in EF ability between 3 and 5 years [12]. Similarly, the application of tasks established in neuropsychological and comparative psychology literatures to the study of EF in children provided further indication of a developmental progression of EF in early childhood and its relation to the development of PFC [13-15]. A review of the developmental sensitivity of tasks appropriate for use with preschool children indicated pronounced ceiling and floor effects on most EF measures, prompting the development of measures of EF appropriate for longitudinal use $[16,17]$.

\section{Reciprocity between EF and academic ability}

Demonstrations of relations between EF and academic ability, including aspects of reading [18] as well as math [19] have been accompanied by a small but growing number of studies examining reciprocal relations between EF and academic content. Cross-lagged path analyses have shown that the development of EF and the development of math and to some extent reading are mutually influential. That is, $\mathrm{EF}$ at the beginning of the prekindergarten (preK) or kindergarten year predicts aspects of math and reading at the end of the school year over and above math and reading ability at the beginning of the year. And reciprocally, aspects of math and reading at the beginning of the year predict EF over and above a measure of $\mathrm{EF}$ at the beginning of the year $[20 \bullet, 21]$.

\section{Trainability of executive function}

Reciprocity between the development of EF and the development of academic ability is consistent with ongoing demonstrations, primarily in adults but also in children to some extent, indicating that EF, in particular WM, is trainable $[22,23,24 \bullet]$. Experiments demonstrating that $\mathrm{EF}$ is trainable through repeated practice on $\mathrm{EF}$ tasks bolsters the idea that educational approaches that include a focus on EF can improve EF while also improving academic ability, particularly in aspects of subjects that make high demands on reasoning, such as transitivity and flexibility in problem solving in mathematics and phonology and passage comprehension in reading. 
Demonstrations of the trainability of EF, both directly through repeated practice on EF tasks, or indirectly through academic learning that requires $\mathrm{EF}$, is highly consistent with the neurobiology of EF. Although PFC develops rapidly in early childhood, it is among the last areas of cortex to reach maturity [25], continuing to undergo changes in gray matter and connectivity into young adulthood. The development of PFC is also characterized by changes in the strength of connectivity with multiple brain regions, such as parietal cortex, limbic structures, namely the amygdala and hippocampus, and the basal ganglia $[26,63,65]$.

Repeated practice on EF tasks, either directly or embedded in academic learning would be expected to strengthen the underlying neural connectivity associated with the coordination of information. This has been clearly demonstrated for direct training of EF through repeated practice on a visual-spatial WM task [27,28]. The development of connectivity between PFC and parietal cortex underlies advances in visual-spatial WM [29]. Notably, although repeated practice on WM tasks has been shown to improve performance on visualspatial WM tasks and closely related tasks, what is referred to as near transfer, findings for far transfer, that is, to mathematics ability or the ability to manage attention and behavior are mixed [30,31].

\section{Application of research on EF to prekindergarten education}

A focus on the connectivity of PFC with regions throughout the brain is central to educational approaches that seek to enhance educational outcomes in part by enhancing $\mathrm{EF}$ [32••]. The association of PFC with reasoning and self-regulation abilities provides a compelling example of the connection between research in neuroscience and research in education. The development of the ability to regulate emotion and to maintain an optimal level of attention in the service of academic learning is a primary goal of early elementary education. By the time children enter first grade, if not kindergarten [33], they are required to begin to be able to manage emotion and attention in ways that support goal-directed learning. As such, one objective for high quality prekindergarten education is to provide structured activities for children that assist with the development of EF abilities that make this possible.

One major focus of the effort to foster the development of $\mathrm{EF}$ in prekindergarten is language development, both expressive and receptive. The development of a rich and varied vocabulary and syntax provides a foundation for reasoning abilities and the capacity to reflect on experience and information. A classic theory of the development of EF focuses specifically on the development of language in childhood [34]. Another major focus of this effort in preK education is structured play [35,36•]. Structured play provides children with the opportunity to engage in purposeful goal-directed activity that is fun and engaging. Structured play provides opportunities to sustain attention and to hold information in mind in the context of peer interaction. When fostered appropriately, structured play assists children in connecting current experience with prior experience in goal-directed, future oriented activities; a classic definition of EF. A third focus of effort is to focus on emotion regulation [37,38]. Specifically, to provide children with knowledge of and strategies that can be used to regulate emotion and to reflect as well as to take the perspective of others when experiencing emotion. 


\section{Examples of effective prekindergarten programs}

Effective, high quality preK programs combine a focus on language development with a focus on play and emotion. Demonstrations of the effectiveness of the few programs that have directly targeted EF in this way have for the most part been accomplished with populations of preschool children at high risk for early school failure due to poverty. For example, the Research-based, Developmentally Informed program (Project REDI) combined a focus on language development through a technique known as dialogic reading [39] with a focus on emotion regulation through a program known as the Promoting Alternative Thinking Skills (PATHS) program [40]. Evaluation of REDI indicated that children in US federally subsidized preschool classrooms for children in poverty (Head Start) that were randomly assigned to implement the program had higher vocabulary, emergent literacy, emotional understanding, social problem solving, social behavior, and engagement in learning [41]. Some effects on social-emotional outcomes were largest for children with low levels of EF in the fall of prekindergarten year [42].

Effects on school readiness through a focus on emotion regulation and emotion knowledge are provided through the evaluation of the Chicago School Readiness Project (CSRP). This program provided training for teachers in the management of behavior problems along with a classroom mental health consultant with the goal of improving the emotional climate of the classroom. Results indicated that Head Start classrooms that were randomly assigned to the implement the program had higher positive emotional climate and lower negative climate and that children in these classrooms had fewer behavior problems [43]. Further analyses indicated that children in the treatment classrooms had higher levels of EF, lower levels of impulsivity and inattention, and that effects on $\mathrm{EF}$ and attention mediated program effects on academic readiness for kindergarten in math, literacy, and language [44••].

Evaluation of a third program, known as Tools of the Mind [45], combines an explicit focus on EF with a focus on language and structured play. An early evaluation of Tools with a sample of children in poverty randomly assigned to classrooms implementing Tools indicated substantial effects of the program on EF [46] with limited evidence of effects on language ability and academic readiness [47]. A subsequent evaluation of the Tools program with a middle-income sample of children in classrooms randomly assigned to implement the program, however, indicated no effect on any aspect of children's readiness for school [48•].

Whether the absence of effects in the evaluation of the Tools program with a middle-income sample was due to implementation with children generally not at risk for early school difficulty or due to problems with the implementation of the program, or both, is not clear. Some insight can be gained, however, from an evaluation of the kindergarten version of Tools of the Mind in which children in kindergarten classrooms in schools randomly assigned to implement the program were shown to have modestly better EF and math and reading ability at the end of kindergarten. Effects of the program on EF and on reasoning ability and vocabulary, however, were substantial for children in high poverty schools as indicated by the percent of students eligible for free or reduced price lunch. Effect sizes were approximately .3-.6 of a standard deviation (one SD is approximately equal to a year of growth) for children at higher risk for early school failure. Follow-up of this sample in the 
fall of first grade indicated effects for all children in Tools classrooms on growth in reading and growth in vocabulary, indicating that children receiving Tools of the Mind in kindergarten were increasing faster in their learning [49•].

\section{Conclusion}

In conclusion, the focus on the development of $\mathrm{EF}$ in preK education is relevant to all children but perhaps most importantly, provides a basis for addressing income-related disparities in school readiness and early school achievement. This is because children in high poverty homes are at risk for poor school readiness and early school difficulty not only from reduced language stimulation [50••] and reduced opportunities for learning among a host of other disadvantages [51] but also from an excess of stress and injurious effects of stress on EF and the regulation of emotion and behavior [52]. Several studies have shown that poverty is physiologically stressful for children and that effects of poverty on the stress response mediate to some extent effects of poverty on EF [53,54••]. Therefore, the provision of high quality early education focusing on EF is most relevant and pressing for children in poverty.

One important direction for future research on prekindergarten education is the inclusion of measures of brain as well as behavior in evaluations of effective programs. With the advent of electrophysiological techniques appropriate for field setting these methods can be incorporated into evaluations of programs such as REDI, PATHS, CSRP, and Tools, described above, as well as many others. Doing so can increase the specificity with which program effects are demonstrated. For example, using evoked response potentials, evaluation of a program focused on selective attention for preschool children in poverty demonstrated effects at the neural as well as behavioral levels from the combination of a parenting program with attention training activities for children [55••]. Measures of stress response physiology, using saliva collection to assay levels of markers such as cortisol, or recording of heart rate variability and skin conductance might provide greater specificity and insight into the physiological processes through which effective prekindergarten programs are affecting children's development. Several studies have indicated in high-risk samples of children that programs that increased the quality of care that children receive from parents is associated with beneficial alternations to diurnal activity of the HPA axis, HPA axis reactivity to challenge, or both [56-58].

To date, of the evaluations of the programs described above, only the kindergarten evaluation of Tools included saliva collection during the mid-morning in school to assay cortisol.

Analyses indicated that children in treatment classrooms in high poverty schools had higher levels of cortisol relative to children in the control condition. This finding is consistent with the facilitative role of cortisol in energy utilization and support for engagement in learning. Notably children in poverty are at risk for high allostatic load [59] that can bias the stress response to be less flexible in response to environmental demand such as schooling. Given the role of stress related neuromodulators, dopamine and norepinephrine [60], as well as the direct activity of glucocorticoids in areas of PFC that support EF, a focus on neuroscience in the evaluation of prekindergarten education may be an important next step in determining not only what works best for children at high risk, but also for coming to conclusions about 
mechanisms through which effective programs are working. Several papers have shown that brain development is altered in children in poverty, most likely through the mechanism of stress $[61 \bullet \cdot 62]$. Effects of stress and poverty on children's developing brains, however, are reversible. Research to determine the extent of reversibility and potential for longer-term change is a pressing scientific priority. A focus on EF and its underlying neurobiology can help to meet this important goal.

\section{Acknowledgments}

Support for this research was provided by the National Institute of Child Health and Human Development grants R01 HD51502 and P01 HD39667 with co-funding from the National Institute on Drug Abuse, by Institute of Education Sciences grants R305A100058 and R324A120033, and by grant 90YR0057 from the US Administration for Children and Families.

\section{References and recommended reading}

Papers of particular interest, published within the period of review, have been highlighted as:

- of special interest

$\bullet$ of outstanding interest

1. Fuster JM. The Prefrontal Cortex 4th. San Diego, CA: Academic Press; 2008

2. Miller EK, Cohen JD. An integrative theory of prefrontal cortex function. Annu Rev Neurosci. 2001; 24:167-202. [PubMed: 11283309]

3. Luria AR. Higher Cortical Functions in Man Tavistock; London: 1966

4. Waltz JA, Knowlton BJ, Holyoak KJ, Boone KB, Mishkin FS, de Menezes Santos M, Miller BL. A system for relational reasoning in human prefrontal cortex. Psychol Sci. 1999; 10:119-125.

5. Blair C. School readiness: integrating cognition and emotion in a neurobiological conceptualization of child functioning at school entry. Am Psychol. 2002; 57:111-127. [PubMed: 11899554]

6. Duncan J, Burgess P, Emslie H. Fluid intelligence after frontal lobe lesions. Neuropsychologia. 1995; 33:261-268. [PubMed: 7791994]

7. Blair C, Razza RP. Relating effortful control, executive function, and false-belief understanding to emerging math and literacy ability in kindergarten. Child Dev. 2007; 78:647-663. [PubMed: 17381795]

8. Clark CA, Pritchard VE, Woodward LJ. Preschool executive functioning abilities predict early mathematics achievement. Dev Psychol. 2010; 46:1176. [PubMed: 20822231]

9. Espy KA, McDiarmid MM, Cwik MF, Stalets MM, Hamby A, Senn TE. The contribution of executive functions to emergent mathematic skills in preschool children. Dev Neuropsychol. 2004; 26:465-486. [PubMed: 15276905]

10. McClelland MM, Cameron CE, Connor CM, Farris CL, Jewkes AM, Morrison FJ. Links between behavioral regulation and preschoolers' literacy, vocabulary, and math skills. Dev Psychol. 2007; 43:947-959. [PubMed: 17605527]

11. Verdine BN, Golinkoff RM, Hirsh-Pasek K, Newcombe NS, Filipowicz AT, Chang A. Deconstructing building blocks: preschoolers' spatial assembly performance relates to early mathematical skills. Child Dev. 2014; 85:1062-1076. [PubMed: 24112041]

12. Zelazo PD, Frye D, Rapus T. An age-related dissociation between knowing rules and using them. Cognit Dev. 1996; 11:37-63.

13. Diamond A, Goldman-Rakic PS. Comparison of human infants and rhesus monkeys on Piaget's AB task: evidence for dependence on dorsolateral prefrontal cortex. Exp Brain Res. 1989; 74:2440. [PubMed: 2924839] 
14. Diamond A, Taylor C. Development of an aspect of executive control: development of the abilities to remember what I said and to "Do as I say, not as I do". Dev Psychobiol. 1996; 29:315-334. [PubMed: 8732806]

15. Luciana M, Conklin HM, Hooper CJ, Yarger RS. The development of nonverbal working memory and executive control processes in adolescents. Child Dev. 2005; 76:697-712. [PubMed: 15892787]

16. Zelazo PD, Anderson JE, Richler J, Wallner-Allen K, Beamont JL, Weintraub S. NIH toolbox cognition battery (CB): measuring executive function and attention. Monogr Soc Res Child Dev. 2013; 78doi: 10.1111/Mono.12039

17. Willoughby MW, Wirth RJ, Blair C, FLP Investigators. Executive function in early childhood: longitudinal measurement invariance and developmental change. Psychol Assess. 2012; 24:418431. [PubMed: 22023561]

18. Kieffer MJ, Vukovic RK, Berry D. Roles of attention shifting and inhibitory control in fourth-grade reading comprehension. Read Res Q. 2013; 48:333-348.

19. Blair C, Ursache A, Greenberg M, Vernon-Feagans L, FLP Investigators. Multiple aspects of selfregulation uniquely predict mathematics ability in the early elementary grades. Dev Psychol. 2015; 51:459-472. [PubMed: 25688999]

20•. Fuhs MW, Nesbitt KT, Farran DC, Dong N. Longitudinal associations between executive functioning and academic skills across content areas. Dev Psychol. 2014; 50:1698. Empirical demonstration of reciprocal relations between language development and the development of EF in early childhood. [PubMed: 24749550]

21. Welsh JA, Nix R, Bierman K, Blair C, Nelson K. The development of executive function and gains in academic school readiness for children in low-income families. J Educ Psychol. 2010; 102:4353. [PubMed: 20411025]

22. Jaeggi SM, Buschkuehl M, Jonides J, Shah P. Short-and long-term benefits of cognitive training. Proc Natl Acad Sci USA. 2011; 108:10081-10086. [PubMed: 21670271]

23. Klingberg T. Training and plasticity of working memory. Trends Cogn Sci. 2010; 14:317-324. [PubMed: 20630350]

24•. Mackey AP, Hill SS, Stone SI, Bunge SA. Differential effects of reasoning and speed training in children. Dev Sci. 2011; 14:582-590. Demonstrated effects of games (computerized and noncomputerized) on reasoning and speed of processing abilities in 7-9 year old children from poverty homes. [PubMed: 21477196]

25. Toga AW, Thompson PM, Sowell ER. Mapping brain maturation. Trends Neurosci. 2006; 29:148159. [PubMed: 16472876]

26. Barbas H, Zikopoulos B. The prefrontal cortex and flexible behavior. Neuroscientist. 2007; 13:532-545. [PubMed: 17901261]

27. Olesen PJ, Westerberg H, Klingberg T. Increased prefrontal and parietal activity after training of working memory. Nat Neurosci. 2004; 7:75-79. [PubMed: 14699419]

28. McNab F, Varrone A, Farde L, Jucaite A, Bystritsky P, Forssberg H, Klingberg T. Changes in cortical dopamine D1 receptor binding associated with cognitive training. Science. 2009; 323:800802. [PubMed: 19197069]

29. Klingberg T. Development of a superior frontal-intraparietal network for visuo-spatial working memory. Neuropsychologia. 2006; 44:2171-2177. [PubMed: 16405923]

30. Shipstead Z, Redick TS, Engle RW. Is working memory training effective? Psychol Bull. 2012; 138:628-654. [PubMed: 22409508]

31. Spencer-Smith M, , Klingberg T. Benefits of a working memory training program for inattention in daily life: a systematic review and meta-analysis; PLOS ONE 2015 e0119522

32••. Diamond A, Lee K. Interventions shown to aid executive function development in children 4 to 12 years old. Science. 2011; 333:959-964. An influential review of multiple programs that have demonstrated the trainability of EF in childhood. [PubMed: 21852486]

33. Bassok D, , Rorem A. EdPolicyWorks University of Virginia; 2014Is Kindergarten the New First Grade The Changing Nature of Kindergarten in the Age of Accountability.

34. Vygotsky LS. Thought and Language Cambridge, MA: MIT Press; 1986rev ed. 
35. Fisher KR, Hirsh-Pasek K, Newcombe N, Golinkoff RM. Taking shape: supporting preschoolers' acquisition of geometric knowledge through guided play. Child Dev. 2013; 84:1872-1878. [PubMed: 23534446]

36•. Lillard AS, Lerner MD, Hopkins EJ, Dore RA, Smith ED, Palmquist CM. The impact of pretend play on children's development: a review of the evidence. Psychol Bull. 2013; 139:1-34. Reviewed studies examining effects of various types of play on children's development and noted mixed effects and methodological problems associated with the study of children's play. [PubMed: 22905949]

37. Raver C. Young children's emotional development and school readiness. SRCD Soc Policy Rep. 2002; 16:3-19.

38. Trentacosta CJ, Izard CE. Kindergarten children's emotion competence as a predictor of their academic competence in first grade. Emotion. 2007; 7:77. [PubMed: 17352565]

39. Whitehurst GJ, Epstein JN, Angell AL, Payne AC, Crone DA, Fischel JE. Outcomes of an emergent literacy intervention in Head Start. J Educ Psychol. 1994; 86:542.

40. Domitrovich CE, Cortes RC, Greenberg MT. Improving young children's social and emotional competence: a randomized trial of the preschool "PATHS" curriculum. J Prim Prevent. 2007; 28:67-91.

41. Bierman KL, Domitrovich CE, Nix RL, Gest SD, Welsh JA, Greenberg MT, Blair C, Nelson KE, Gill S. Promoting academic and social-emotional school readiness: the head start REDI program. Child Dev. 2008; 79:1802-1817. [PubMed: 19037951]

42. Bierman KL, Nix RL, Greenberg MT, Blair C, Domitrovich CE. Executive functions and school readiness intervention: impact, moderation, and mediation in the Head Start REDI program. Dev Psychopathol. 2008; 20:821-843. [PubMed: 18606033]

43. Raver CC, Jones SM, Li-Grining CP, Zhai F, Metzger M, Solomon B. Targeting children's behavior problems in preschool classrooms: a cluster-randomized controlled trial. J Consult Clin Psychol. 2009; 77:302-316. [PubMed: 19309189]

44••. Raver CC, Jones SM, Li-Grining CP, Zhai F, Bub K, Pressler E. CSRP's impact on low-income preschoolers' pre-academic skills: self-regulation as a mediating mechanism. Child Dev. 2011; 82:362-378. Randomized controlled trial demonstration that a preschool program focusing on emotion regulation and the emotion climate of the classroom could lead to program related improvements in EF and academic and social-emotional readiness for school. [PubMed: 21291447]

45. Bodrova E, , Leong DJ. Tools of the Mind: The Vygotskian Approach to Early Childhood Education New York: Merrill/Prentice Hall; 2007

46. Diamond A, Barnett WS, Thomas J, Munro S. Preschool program improves cognitive control. Science. 2007; 318:1387-1388. [PubMed: 18048670]

47. Barnett WS, Jung K, Yarosz DJ, Thomas J, Hornbeck A, Stechuk R, Burns S. Educational effects of the Tools of the Mind curriculum: a randomized trial. Early Childhood Res Q. 2008; 23:299_ 313.

48. Wilson S, , Farran D. Experimental evaluation of the Tools of the Mind curriculum Washington, DC: Paper presented at the Society for Research on Educational Effectiveness Spring 2012 Conference; 2012 Mar. Randomized controlled trial evaluation of the Tools of the Mind prekindergarten program that found no effect of the program on any aspect of children's development or readiness for school.

49. Blair C, Raver CC. Closing the achievement gap through modification of neurocognitive and neuroendocrine function: results from a cluster randomized controlled trial of an innovative approach to the education of children in kindergarten. PLOS ONE. 2014; 9:e112393. .

Demonstrated that executive function, reasoning, vocabulary, reading, and math ability can be enhanced in kindergarten through a focus on structured sociodramatic play. Effects were large for children in high poverty schools. Effects on reading and vocabulary were sustained into the first grade. doi: 10.1371/journal.pone.0112393 [PubMed: 25389751]

50••. Fernald A, Marchman VA, Weisleder A. SES differences in language processing skill and vocabulary are evident at 18 months. Dev Sci. 2013; 16:234-248. Empirical demonstration that the effect of poverty on language development is evident in infancy through the measurement of the efficiency with which language stimulation is processed. [PubMed: 23432833] 
51. Duncan GJ, Brooks-Gunn J. Family poverty, welfare reform, and child development. Child Dev. 2000; 71:188-196. [PubMed: 10836573]

52. Evans GW. The environment of childhood poverty. Am Psychol. 2004; 59:77. [PubMed: 14992634]

53. Blair C, Granger D, Willoughby M, Mills-Koonce R, Cox M, Greenberg MT, Kivlighan K, Fortunato C, FLP Investigators. Salivary cortisol mediates effects of poverty and parenting on executive functions in early childhood. Child Dev. 2011; 82:1970-1984. [PubMed: 22026915]

$54 \bullet$. Evans GW, Schamberg MA. Childhood poverty, chronic stress, and adult working memory. Proc Natl Acad Sci USA. 2009; 106:6545-6549. Longitudinal demonstration of relations among the experience of poverty in childhood, allostatic load, and working memory ability in early adolescence. [PubMed: 19332779]

55••. Neville H, Stevens C, Pakulak E, Bell T, Fanning J, Klein S, Isbell E. Family-based training program improves brain function, cognition, and behavior in lower socioeconomic status preschoolers. Proc Natl Acad Sci USA. 2013; 110:12138-12143. Demonstrated effects of a program focused on selective attention for preschool children in poverty at the neural as well as behavioral levels from the combination of information for parents with attention training activities for children. [PubMed: 23818591]

56. Brotman LM, Gouley KK, Huang KY, Kamboukos D, Fratto C, Pine DS. Effects of a psychosocial family-based preventive intervention on cortisol response to a social challenge in preschoolers at high risk for antisocial behavior. Arch Gen Psychiatry. 2007; 64:1172-1179. . DOI: 10.1001/ archpsyc.64.10.1172 [PubMed: 17909129]

57. Dozier M, Peloso E, Lewis E, Laurenceau J, Levine S. Effects of an attachment-based intervention on the cortisol production of infants and toddlers in foster care. Dev Psychopathol. 2008; 20:845859. [PubMed: 18606034]

58. Fisher PA, Gunnar MR, Dozier M, Bruce J, Pears KC. Effects of therapeutic interventions for foster children on behavioral problems, caregiver attachment, and stress regulatory neural systems. Ann N Y Acad Sci. 2006; 1094:215-225. [PubMed: 17347353]

59. McEwen BS. The neurobiology of stress: from serendipity to clinical relevance. Brain Res. 2000; 886:172-189. [PubMed: 11119695]

60. Arnsten AF. Stress signaling pathways that impair prefrontal cortex structure and function. Nat Rev Neurosci. 2009; 10:410-422. [PubMed: 19455173]

61••. Hair NL, Hanson JL, Wolfe BL, Pollak SD. Association of child poverty, brain development, and academic achievement. JAMA Pediatr. 2015; 169:822-829. Analyzed structural MRI data from a longitudinal cohort and found that poverty related variation in regions that underlie EF were associated with poverty related differences in school readiness and academic achievement. [PubMed: 26192216]

62. Hanson JL, Hair N, Shen DG, Shi F, Gilmore JH, Wolfe BL, et al. Family poverty affects the rate of human infant brain growth. PLoS ONE. 2013; 8:e80954 . doi: 10.1371/journal.pone.0080954 [PubMed: 24349025]

63. Bull R, Scerif G. Executive functioning as a predictor of children's mathematics ability: inhibition, switching, and working memory. Dev Neuropsychol. 2001; 19:273-293. [PubMed: 11758669]

64. Gee DG, Humphreys KL, Flannery J, Goff B, Telzer EH, Shapiro M, Hare TA, Bookheimer SY, Tottenham N. A developmental shift from positive to negative connectivity in human amygdalaprefrontal circuitry. J Neurosci. 2013; 33:4584-4593. [PubMed: 23467374] 